\title{
The Characteristics of Ultrasonic Wave Transmitted Through Drying Wood*1
}

\author{
Ho-Yang Kang*2†
}

\begin{abstract}
The possibility of using the properties of an ultrasonic wave as a means for monitoring the moisture content of a board during drying was investigated. The ultrasonic wave signals are influenced by moisture content and other factors such as temperature, moisture gradient and coupling area. The effect of temperature was examined by measuring the transit times, amplitudes and velocities of ultrasonic waves transmitted through air, a metal bar and a board at various temperatures. The effect of a moisture gradient was studied using a model specimen composing five wood pieces of various moisture contents. The velocity and amplitude of the ultrasonic waves transmitted through air increase with temperature, while those through a metal bar and a board decrease. It was confirmed that the temperature effect is partially attributed to the change of transducer's properties. The effect of a moisture gradient on the velocity of an ultrasonic wave varies with the average moisture content of a board. As the dimension of the end face of a board increases the velocity of an ultrasonic wave increases and low frequency components more dominates than high frequency components. The transit times of ultrasonic waves transmitted through a board during kiln drying reflect the temperature steps in the drying schedule and the transducer temperatures.
\end{abstract}

Keywords : Ultrasonic wave, temperature, frequency component, PUNDIT

\section{INTRODUCTION}

It has been known that the velocity of an ultrasonic wave varies with the moisture content of wood (Booker et al., 1996; Wang et al., 2002; van Dyk and Rice, 2006). James et al. (1982) pointed out that if the initial room-temperature value of ultrasonic velocity at a known moisture content is determined, subsequent changes in the average moisture content of the specimen can be estimated from the change in ultrasonic velocity. Simpson and Wang (2001) suggested that speed of sound measurements have good potential for control of hardwood kiln schedules at moisture contents above $30 \%$.

The velocity of an ultrasonic wave has been observed to decrease as temperature is increased (James et al., 1982; Sandoz 1993), which was

\footnotetext{
*1 Received on May 17, 2010; accepted on October 13, 2010

This study was supported by Technology Development Program of the Ministry of Agriculture and Forestry, Republic of Korea

*2 College of Agriculture and Life Science, Chungnam National University, Daejeon 305-764, Korea

† Corresponding author : Ho-Yang Kang (e-mail: hykang@cnu.ac.kr)
} 
attributed by James (1961) to the decrease of the MOE with increasing temperature. Kang and Booker (2002) revealed that variations in transducer temperature cause changes in waveform, amplitude and transit time of a transmitted signal and have to be corrected for.

When an ultrasonic wave propagates through a dimension lumber a moisture gradient in wood is also an influencing factor on its velocity. Mishiro (1995) reported that when a moisture gradient is perpendicular to the ultrasonic wave direction its velocity was more dependent on that of the layer with the lowest moisture content.

The purpose of this study is to investigate factors influencing on the characteristics of the ultrasonic wave transmitted through a dimension lumber during drying and to find the feasibility of utilizing the ultrasonic technology for monitoring the moisture content of a board during drying.

\section{MATERIALS and METHODS}

\subsection{Equipment}

The velocity of an ultrasonic wave in wood can be measured by the resonant frequency technique as well as by impact and ultrasonic wave devices (Beall, 2002). In this study a commercial ultrasonic wave device known as PUNDIT was used. The PUNDIT consists of a combined pulse generator and timer and a pair of tuned piezoelectric transducers, whose fundamental resonance frequency and diameter are $54.2 \mathrm{kHz}$ and $50 \mathrm{~mm}$, respectively. A Phillips PM3384 combined digital and analog oscilloscope was used to monitor the transmitted ultrasonic signals and to analyze the frequency spectrum.

Vaseline was used as a coupling agent between the transducers and the end faces of the boards, which were end coated with aluminum paint to prevent rapid drying from the end grains. But for the boards not end coated the coupling agent was not used to avoid penetrating.

\subsection{Effect of end Face Dimension}

The lower is the resonance frequency the bigger is the transducer diameter. The transducers of lower resonance frequencies $(<100 \mathrm{kHz})$ are generally used for wood ultrasonic nondestructive testing. It easily happens that the thickness of a board is thinner than the diameter of transducers. The properties of the ultrasonic waves transmitted the boards with various thicknesses were examined.

Since the diameter of the transducers used in this study was $50 \mathrm{~mm}$, the specimens of $50 \mathrm{~mm}$ in both thickness and width and $200 \mathrm{~mm}$ in length were cut from quarter sawn boards of air dried radiata pine. Two specimens were taken from each of sapwood and heartwood. The transit times and waveforms of the ultrasonic waves transmitted parallel to the grain were collected by using the system consisting of PUNDIT, the digital oscilloscope and a PC.

After the data collection, the specimens of 50 $\times 50 \times 200 \mathrm{~mm}^{3}$ were cut down to the next largest end face dimension while the length of the specimens was uncut. This procedure was repeated until the end face dimension reached to be $20 \times 20 \mathrm{~mm}^{2}$. In addition to the two end face dimensions of $50 \times 50$ and $20 \times 20 \mathrm{~mm}^{2}$, four different end face dimensions were measured in this experiment: $50 \times 40,50 \times 20,40$ $\times 20$ and $30 \times 20 \mathrm{~mm}^{2}$.

\subsection{Effect of Moisture Gradient}

For this experiment 5 layered model specimens with various moisture gradients were made. Twenty one specimens of $5 \mathrm{~mm}$ in thickness, $50 \mathrm{~mm}$ in width and $150 \mathrm{~mm}$ in length were cut 
from the quarter sawn boards of air dried radiata pine sapwood. They were divided into 7 groups and were conditioned at the equilibrium moisture contents of $30,25,20,15,10,5$ and $0 \%$ in a humidity chamber at a room temperature. One specimen of each group was oven dried to determine its correct moisture content. Each group has two specimens of the same moisture content.

A model specimen consisted of five specimens: two shells, two middle and one core specimens. They were tied firmly with a rubber-band. The dimension of the model specimen was $25 \mathrm{~mm}$ thick, $50 \mathrm{~mm}$ wide and $150 \mathrm{~m}$ long. As a typical wood the moisture gradient of the model specimens were mirror imaged. A total of 210 model specimens were made and their transit times of longitudinal ultrasonic waves were measured by the PUNDIT.

\subsection{Effect of Temperature}

For this experiment, ultrasonic wave transmitted air or a metal bar in the range of temperatures from 25 to $75^{\circ} \mathrm{C}$ in an oven. The cycle of oven temperature repeated twice. A thermocouple was glued to one of the two transducers. Transit times of ultrasonic waves and transducer temperature were transmitted to a PC.

For air transmission, a pair of transducers was set $12 \mathrm{~mm}$ apart on a wooden platform. There was nothing except air between the transducers. The dimension of the metal bar used in this experiment was $50 \mathrm{~mm}$ in diameter and $160 \mathrm{~mm}$ in length.

\subsection{Elimination of the Temperature Effect}

It has been found that the temperature of a transducer influences the velocity of an ultrasonic wave transmitted through wood during
(Kang and Booker, 2002). A special drying unit was made to eliminate such temperature effect. The transducers attached to a board were placed outside the drying unit, whose dimensions were $60 \mathrm{~cm}$ in height, $22 \mathrm{~cm}$ in width and $50 \mathrm{~cm}$ in length.

The temperature of a board can be increased to $75^{\circ} \mathrm{C}$ with a heater of $1 \mathrm{~kW}$ capacity and was monitored with a thermocouple implanted in the middle of the board. A digital balance of $16 \mathrm{~kg}$ capacity was placed at the bottom of the drying unit and was interfaced with a PC to continuously read the total weight of the drying unit and board. Two runs were conducted with the boards of radiata pine sapwood, whose dimensions were $45 \mathrm{~mm}$ in thickness, $105 \mathrm{~mm}$ in width and $620 \mathrm{~mm}$ in length.

\subsection{Application of an Ultrasonic Wave to Measure the Moisture Content of Wood during Drying}

In this experiment the weight and transit time of boards were simultaneously recorded during drying in a kiln. The temperatures of boards and transducers were also recorded by the data logger. In the middle of this experiment automatic systems for recording the weight and transit time of boards were developed, so that they were recorded every 10 minutes during the night as well as the daytime.

Since this experiment was conducted over a long period of time some of the specimens were not matched, but their nominal green dimensions were about $120 \times 40 \times 540 \mathrm{~mm}$. They consisted of green radiata pine sapwood. Both ends of the boards were coated with two layers of aluminum paint to prevent end drying. This coating may introduce an additional delay in transit time.

The transducers and thermocouples were attached to and implanted in the boards as shown 


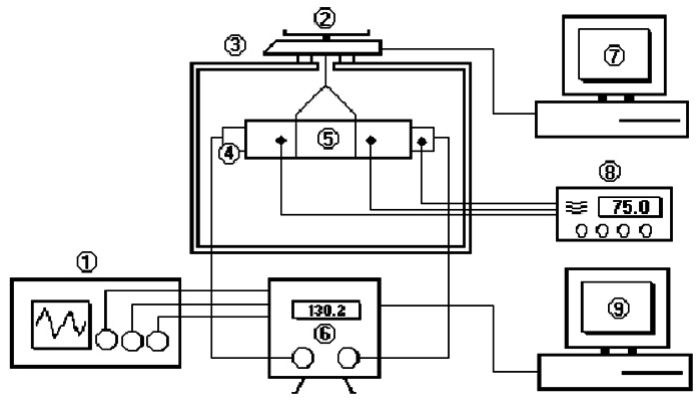

Fig. 1. Diagram of experimental details to measure the ultrasonic velocity of a board during drying in a kiln. 1. Oscilloscope, 2. balance with an interface to a PC, 3. kiln, 4. transducer, 5. board, 6. PUNDIT ultrasonic timer, 7. PC with an interface to balance, 8. data logger for thermocouples, 9. PC with an interface to PUNDIT.

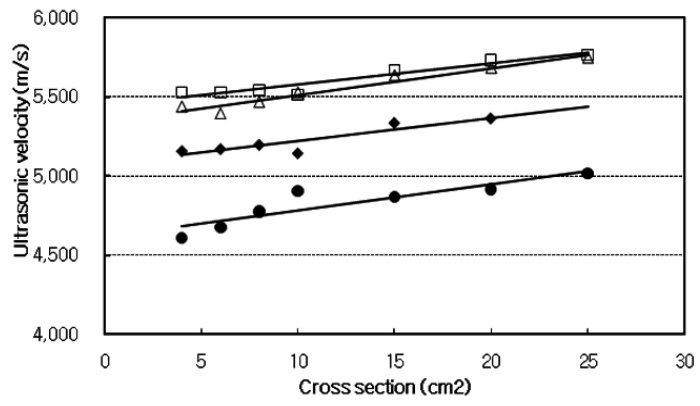

Fig. 2. Ultrasonic velocity of boards with various cross sections. Empty and solid symbols represent respectively heartwood and sapwood specimens of radiata pine.

in the experimental set up (Fig. 1). In the kiln a cradle was used to prevent boards from swaying in the air stream. A total of three runs were conducted in a kiln.

In each run a single board was dried. The average green moisture content and specific gravity based on oven dry weight/green volume of the boards were $160 \%$ and 0.42 , respectively. The boards for the three runs were end matched.
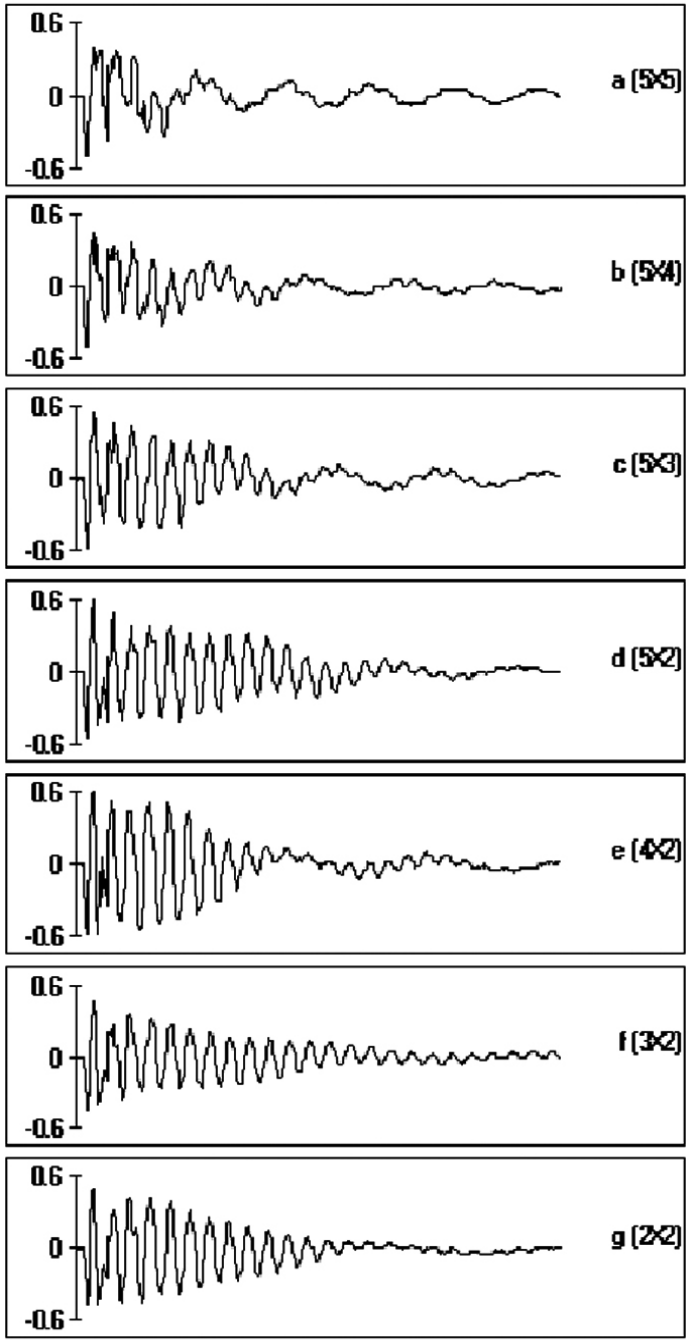

Fig. 3. Waveforms of the ultrasonic waves transmitted through boards with various cross sections. As the cross section decreases high frequency component dominates.

\section{RESULTS and DISCUSSION}

\subsection{Effect of End Face Dimensions}

As the dimension of the end faces of the boards decreases $25(5 \times 5) \mathrm{cm}^{2}$ to $4(2 \times 2)$ $\mathrm{cm}^{2}$ the velocity of ultrasonic waves decreases 
The Characteristics of Ultrasonic Wave Transmitted Through Drying Wood
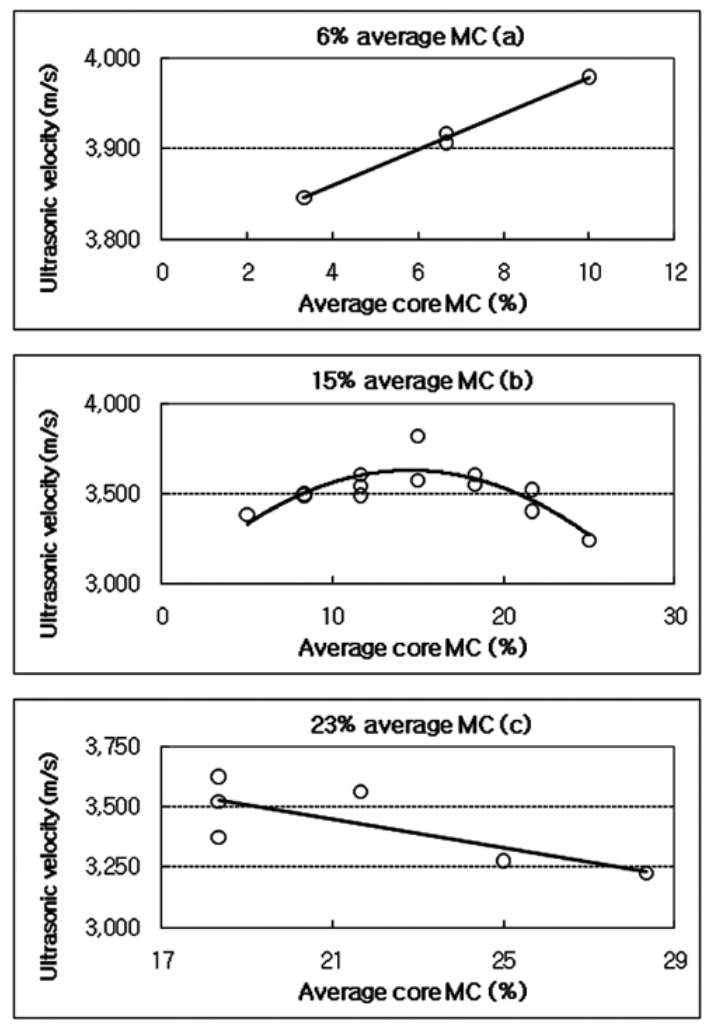

Fig. 4. Typical plots of the ultrasonic wave velocities of the 5 layered model specimens vs. the average moisture contents of their three core layers.

by about $5 \%$ for the specimens of both sapwood and heartwood (Fig. 2). Since the PUNDIT readings would be incorrect when the first received signals don't reach the trigger voltage of $2 \mathrm{mv}$, it is important to confirm this fact by monitoring waveforms with an oscilloscope. Fig. 3 shows that the first negative voltages of all specimens are well above the trigger voltage, but slightly decrease with the decreasing of the dimensions of the end faces, which may be partially attributed to the variation of the ultrasonic velocities.

It is interesting to notice that low frequency components dominate in the $25(5 \times 5) \mathrm{cm}^{2}$

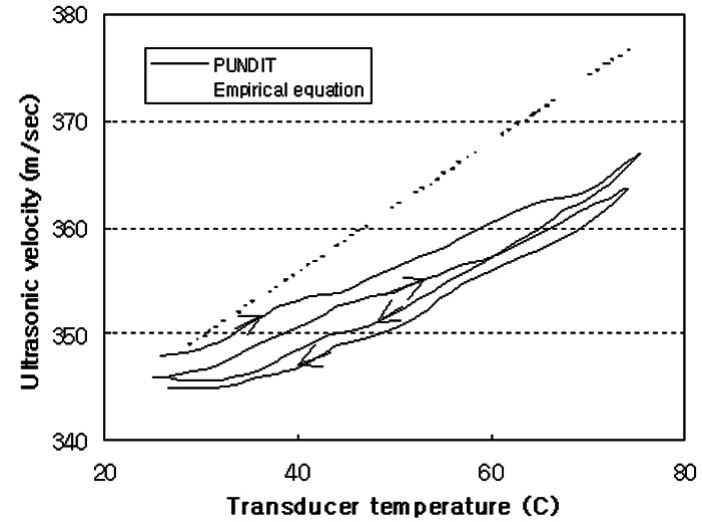

Fig. 5. The velocity of ultrasonic waves transmitted through air. The temperature of air and transducers were cyclically controlled in an oven.

specimens while do high frequency components in the $5(2 \times 2) \mathrm{cm}^{2}$ specimens (Fig. 3).

\subsection{Effect of Moisture Gradient}

The ultrasonic wave velocities of the 210 model specimens are plotted against their average moisture contents in Fig. 4. The wide variation of this plot implies that the velocity of an ultrasonic wave is not affected by only moisture content, but also a moisture gradient of wood.

Fig. 4 shows three typical plots of the ultrasonic velocity of a model specimen versus its core moisture content, the average of inner three specimens. It is interesting that there are three distinct plots variable depending on the average moisture content of a model specimen. At as low as $6 \%$ average moisture content there is a positive relationship between the ultrasonic velocity of a model specimen with its core moisture content of (Fig. 4a), while at as high as $23 \%$ average moisture content there is a negative relationship (Fig. 4c). It can be explained that the longitudinal ultrasonic waves in the model specimens transmit mainly through the shell and core specimens, respectively, at low 


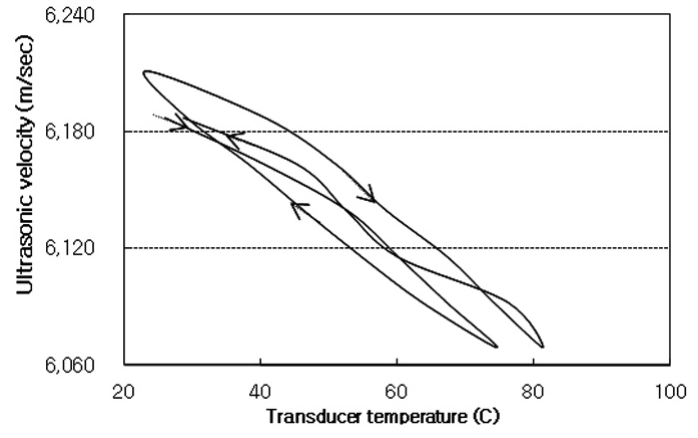

Fig. 6. The velocity of ultrasonic waves transmitted through a metal bar. The temperature of a metal bar and transducers were cyclically controlled in an oven.

and high moisture contents. However at 15\% average moisture content there is parabolic plot with a peak where the core moisture content is almost the same as the shell's.

\subsection{Effect of Temperature}

The velocity of ultrasonic waves through air shows hysteresis with the cyclic change of temperature (Fig. 5). Like a sorption hyteresis loop the ultrasonic velocity curve of the initial heating is appreciably above that of subsequent cooling, which is below that of the second heating. The ultrasonic wave velocities through air obtained in this experiment are similar to the reference values calculated with an empirical equation (Weast, 1985) at low temperature, but diverge as temperature increases. This is an evidence that the transducers used in this experiment are influenced by temperature. Kang and Booker (2002) proposed that the viscosity of the glue adhering a crystal to a metal casing may change with temperature and this may cause a delay in transit time.

The velocity of ultrasonic waves through a metal bar also shows hysteresis with a negative relationship with temperature (Fig. 6), which is

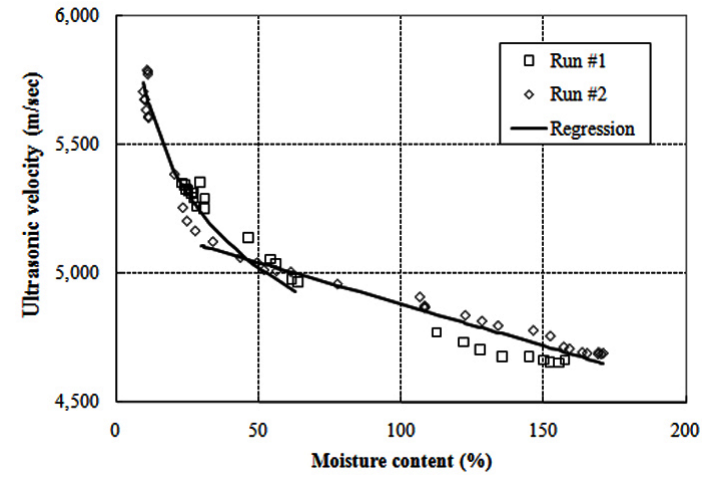

Fig. 7. The ultrasonic wave velocities monitored during the drying of radiata pine boards, to which the transducers were attached and maintained at a room temperature.

opposite to the fact with air. Since the physical properties of a metal bar less change in this temperature range, hysteresis is attributable to the property change of the transducers.

\subsection{Elimination of the Temperature Effect}

The ultrasonic wave velocities of two boards dried from 170 to $11 \%$ moisture content are plotted in Fig. 7. According to Sakai et al. (1990), Sandoz (1993) and Booker et al. (1996), the graphs of ultrasonic velocity versus moisture content consist of two straight line segments intersecting at the fiber saturation point. However, the plots in Fig. 7 look more curvilinear than bilinear. The probable explanation for this is that the above investigators carefully dried their boards to an uniform moisture content, with as small a variation over a cross section as possible. In our investigation the boards were kiln dried so that they are much wetter in the interior than at the surface. This would have the effect of smoothing out the "kink" at the fiber saturation point found by the above investigators. The velocity intersection point of the two line seg- 


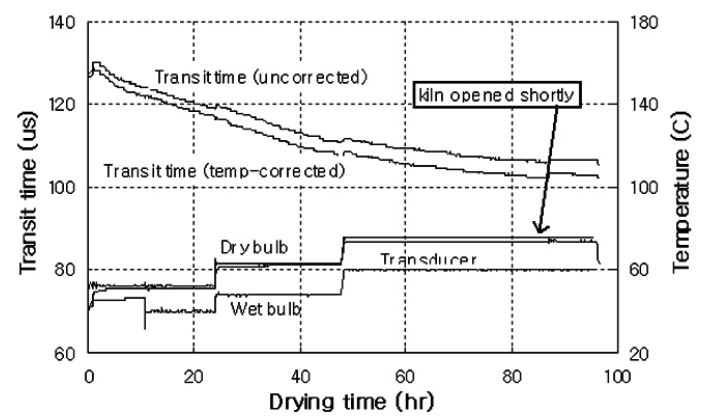

Fig. 8. Graphs of drybulb, wetbulb, and transducer temperature as well as transit time versus drying time for a kiln run. The temperature corrected transit time curve has been corrected for the effect of changes in transducer temperature on transducer delay times.

ments occurs at $46 \%$ moisture content, which is much higher than the fiber saturation point at about $30 \%$ moisture content.

\subsection{Application of an Ultrasonic Wave to Measure the Moisture Content of Wood during Drying}

Among three kiln runs Fig. 8 is the typical graph of the dry bulb, wet bulb and transducer temperatures, and the raw and temperature corrected transit times. The temperature correction equation used in this experiment is the same as Equation 2 in Kang and Booker (2002). The unadjusted experimental transit times reflect the temperature steps in the schedule and the transducer temperature steps. After the temperature correction the transit time curves become smoother except at temperatures above $70^{\circ} \mathrm{C}$, where the temperature correction factor does not offset the temperature effect very well.

Though the fan direction changed every 12 hours Fig. 8 does not reflect it. In contrast, James et al. (1982) found their ultrasonic wave transit time changed with fan direction during kiln drying but they were unable to explain this phenomenon. It can be explained by the effect of transducer temperature on the transit time. In their experiment the kiln load was about 6 by 4 by 8 feet with one board instrumented with transducers, which should be located either side of the load for the convenience of transducer cabling (not described in their paper). Since the temperatures of two sides of the load are different from each other, fan reversal would have changed the transducer temperature, resulting in the observed change of the transit time.

In our investigation transit times were not affected by the fan directions. This is probably due to the fact that in this study only one board at a time was dried in the kiln, so that the fan reversal didn't really change the transducer temperature or drying conditions.

James et al. (1982) also observed that an increase of dry bulb temperature with a step of $20^{\circ} \mathrm{C}$ produced a distinct pulse in the transit time curve and attributed this fact to surface drying of the board. However this is not a good explanation because surface drying of the board occurs slowly and steadily. In contrast the effect of transducer temperature on transit time is distinct and fast.

In Fig. 8 a kiln opening of a few minutes at 87 hours caused a sharp increase in the transit time curve, and a spike in the dry bulb and transducer temperature curves. The surface of a board does not dry substantially during a few minutes. However, the temperature change of both the dry bulb and transducer temperatures was in the nature of a transient spike, while the transit time increase was permanent (Fig. 8). This is still unexplained.

\section{CONCLUSIONS}

Factors influencing the properties of the ultrasonic waves transmitted through wood during kiln drying were investigated. The conclusions 
are as followed:

1) The velocity and amplitude of the ultrasonic waves transmitted through air, a metal bar and a board change with temperature, which is partially attributed to the property change of transducers.

2) The effect of a moisture gradient on the velocity of an ultrasonic wave varies with the average moisture content of a board.

3) As the dimension of the end face of a board increases the velocity of an ultrasonic wave increases and low frequency components more dominates than high frequency components.

4) The graph of ultrasonic velocity versus moisture content seems to be curvilinear rather than bilinear.

5) The transit time of an ultrasonic wave transmitted through a board during kiln drying reflects the temperature steps in the schedule and the transducer temperature steps.

\section{REFERENCES}

1. Beall, F. C. 2002. Overview of the use of ultrasonic technologies in research on wood properties. Wood Science and Technology 36(3): 197 212

2. Booker, R. E., J. Froneberg, and F. Collins. 1996. Variation of sound velocity and dynamic Young's modulus with moisture content in the three principal directions. Proceedings 10th International Symposium on Non-Destructive Testing of Wood, Lausanne, Switzerland, 26 28 August 1996: 279 $\sim 295$.

3. James, W. L. 1961. Internal friction and speed of sound in Douglas-fir. Forest Products Journal 11(9): $383 \sim 390$.

4. James, W. L., R. S. Boone, and W. L. Galligan. 1982. Using speed of sound in wood to monitor drying in a kiln. Forest Products Journal 32(9): $27 \sim 34$.

5. Kang, H. and R. E. Booker. 2002. Variation of stress wave velocity with MC and temperature. Wood Science and Technology 36(1): $41 \sim 54$.

6. Mishiro, A. 1995. Effects ultrasonic velocity in wood and its moisture content I. Effects of moisture gradients on ultrasonic velocity in wood. Mokuzai Gakkaishi 41(12): 1086 1092.

7. Sakai, H., A. Minamisawa, and K. Takagi. 1990. Effect of moisture content on ultrasonic velocity and attenuation in woods. Ultrasonics 28 November: $382 \sim 385$.

8. Sandoz, J. L. 1993. Moisture content and temperature effect on ultrasound timber grading. Wood Science and Technology 27: $373 \sim 380$.

9. Simpson, W. T. and X. Wang. 2001. Relationship between longitudinal stress wave transit time and moisture content of lumber during kiln-drying. Forest Products Journal 51(10): 51 54.

10. van Dyk, H. and R. W. Rice. 2006. Ultrasonic wave velocity as a moisture indicator in frozen and unfrozen lumber. Forest Products Journal 55(6): $68 \sim 72$.

11. Wang, S. Y., C. M. Chiu, and C. J. Lin. 2002. Variations in ultrasonic wave velocity and dynamic young's modulus with moisture content for Taiwania plantation lumber. Wood and Fiber Science 34(3): 370 381.

12. Weast, R. C. 1985. CRC Handbook of Chemistry and Physics 66th Ed. (F-106 p). CRC Press. Boca Ratan, Florida, USA. 